\title{
RESEARCH
}

Open Access

\section{The historical roots and seminal research on health equity: a referenced publication year spectroscopy (RPYS) analysis}

\author{
Qiang Yao ${ }^{1,2+} \mathbb{D}$, Xin $\mathrm{Li}^{3 \dagger}$, Fei Luo ${ }^{4}$, Lianping Yang ${ }^{5}$, Chaojie $\mathrm{Liu}^{2^{*}}$ (D) and Ju Sun ${ }^{1,6^{*}}$
}

\begin{abstract}
Background: Health equity is a multidimensional concept that has been internationally considered as an essential element for health system development. However, our understanding about the root causes of health equity is limited. In this study, we investigated the historical roots and seminal works of research on health equity.

Methods: Health equity-related publications were identified and downloaded from the Web of Science database $(n=$ 67,739, up to 31 October 2018). Their cited references $(n=2,521,782)$ were analyzed through Reference Publication Year Spectroscopy (RPYS), which detected the historical roots and important works on health equity and quantified their impact in terms of referencing frequency.

Results: A total of 17 pronounced peaks and 31 seminal works were identified. The first publication on health equity appeared in 1966. But the first cited reference can be traced back to 1801. Most seminal works were conducted by researchers from the US $(19,61.3 \%)$, the UK $(7,22.6 \%)$ and the Netherlands $(3,9.7 \%)$. Research on health equity experienced three important historical stages: origins (1800-1965), formative (1966-1991) and development and expansion (1991-2018). The ideology of health equity was endorsed by the international society through the World Health Organization (1946) declaration based on the foundational works of Chadwick (1842), Engels (1945), Durkheim (1897) and Du Bois (1899). The concept of health equity originated from the disciplines of public health, sociology and political economics and has been a major research area of social epidemiology since the early nineteenth century. Studies on health equity evolved from evidence gathering to the identification of cost-effective policies and governmental interventions.

Conclusion: The development of research on health equity is shaped by multiple disciplines, which has contributed to the emergence of a new stream of social epidemiology and political epidemiology. Past studies must be interpreted in light of their historical contexts. Further studies are needed to explore the causal pathways between the social determinants of health and health inequalities.
\end{abstract}

Keywords: Health equity, Historical roots, Milestone works, Reference publication year spectroscopy (RPYS)

\section{Background}

Health equity was a cornerstone of the Millennium Development Goals (MDGs) and a major goal in the Sustainable Development Goals (SDGs) [1]. It has been endorsed by many international and national agencies as

\footnotetext{
* Correspondence: C.Liu@latrobe.edu.au; sunju@whu.edu.cn

${ }^{+}$Qiang Yao and Xin Li contributed equally to this work.

${ }^{2}$ School of Psychology and Public Health, La Trobe University, Melbourne, VIC 3086, Australia

${ }^{1}$ School of Political Science and Public Administration, Wuhan University,

Wuhan 430072, Hubei, China

Full list of author information is available at the end of the article
}

an essential element in health system development [2-4]. There is consensus in the international community that health is a fundamental human right [5], and health equity reflects social fairness and justice [6, 7]. Inequity in health can bring detrimental effects on economic development, social vibrancy, and national security [8].

The concept of health equity involves multiple dimensions. In the literature, "health disparity", "health inequality" and "health inequity" are often used interchangeably [8]. They may measure differences in health system structure (e.g. availability of financial and human resources), health 
care delivery (e.g. accessibility and quality of care), or health care outcomes (e.g. individual and population health) across populations. Increasingly, researchers agree that health equity is a more appropriate term for defining health system development goals. This is because inherent biomedical differences in health exist among populations; but health is also determined by socioeconomic factors and the differences in health outcomes caused by these modifiable factors are unacceptable. Therefore, the allocation of health care resources and services should be prioritized toward the socioeconomically disadvantaged. These people are likely to suffer from more health problems and need more care. In health care, equity indicates "equal access to available care for equal need, equal utilization for equal need, and equal quality of care for all" [9]. In other words, health inequity measures needs-adjusted inequality in health [10, 11]. Clearly, the concept of health equity is primarily based on the value judgements of morality, justice and human right norms. The most concise and accessible definition of health inequity was articulated by Whitehead in the early 1990s and Braveman in 2006 as "the systematic, unnecessary, potentially avoidable differences in health or the major socially determined influences on health between groups of people who have different relative positions in social hierarchies according to wealth, power, or prestige, which can be shaped by policies" [11, 12]. Unfortunately, debates about what differences are unnecessary, avoidable, unfair and unjust will never disappear.

Intellectual history is the foundation for studying an area and is helpful for the researcher to understand the key concepts and comprehensive development process of a research area. It gives researchers an insightful perspective into what their work positions and how their work fits into the overall area. The term "health equality" first appeared in the article "Equality and Health" written by Meltsner in 1966 [13]. This article is commonly accepted as the first published health equity study in several bibliometric studies [14-16], despite some differing personal opinions $[17,18]$. However, as a multidisciplinary concept with a long history, the theoretical roots of the term "health equality" can be traced back far before the year of 1966 and has a far-reaching theoretical and practical history. Health equity-related studies had already emerged before the appearance of the terms. At present, the origins or intellectual roots of the concept of health equity is still unclear. A better understanding of the historical context of health equity will render a refreshing perspective on how it all started, in which direction the research field is moving, and what gaps in research need to be filled.

In this study, we investigated the historical roots of health equity studies through identifying the seminal works of relevant research and analyzing publication and referencing trends using the method of Reference Publication
Year Spectroscopy (RPYS) proposed by Marx et al. in 2013 [19]. Such a study is necessary to help researchers develop a better understanding of the origin and evolutionary pathway of health equity studies, which is essential for an adequate interpretation of previous studies, the articulation of new research questions and the adaptation of methodological approaches.

\section{Methods}

We performed a RPYS [19] analysis on health equity studies. It quantified the impact of studies in the area of health equity by analyzing the cited references before and after the term(s) appeared [20]. RYPS assumes that a new research area usually evolves on the basis of previous discussions among researchers in the scientific community; and the relationship of current research to past literature plays a significant role, which is usually expressed in the form of citations [21]. The premise of citation theory is that the more frequently cited scientific publications contribute more to the advancement of knowledge [19]. A citation analysis provides insights into the historical context of science. It offers the opportunity for researchers to trace the origin of a new research area even before its concept and terms are formalized.

RPYS has been successfully used to detect the historical roots, milestone works and evolutionary pathways of a number of research areas, ranging from philosophy to medicine, computer science and climate change [19, 21-32]. For example, RPYS analyses revealed that Garfield is one of the pioneers and most influential researchers in bibliometric studies, and his work was influenced by that of Shepard [32]. To the best of our knowledge, no RPYS studies have ever been conducted in the area of health equity research.

\section{Data source}

Data for this study, including both publications and their cited references, were extracted from the Web of Science (WoS) core collection using the search strategy "TS $=(($ Health OR healthcare) AND (Equit" OR Equalit" OR Inequit* OR Inequalit* OR Disparit*)) AND PY= 1900-2018 AND DOCUMENT TYPES=(Article OR Proceedings Paper OR Review) AND Indexes $=$ SCI-EXPANDED, SSCI, A\&HCI". A total of 67,739 publications from 1966 to 2018 were retrieved on 30th October 2018 (Fig. 1). Full records and cited reference lists (2,521,782 references published from 1800 to 2018) were downloaded for data analyses.

\section{Data analysis}

RPYS was performed to detect the historical roots and important works within the health equity literature. The RPYS analysis assumes that the publication years of the references cited in the literature are not evenly represented; 


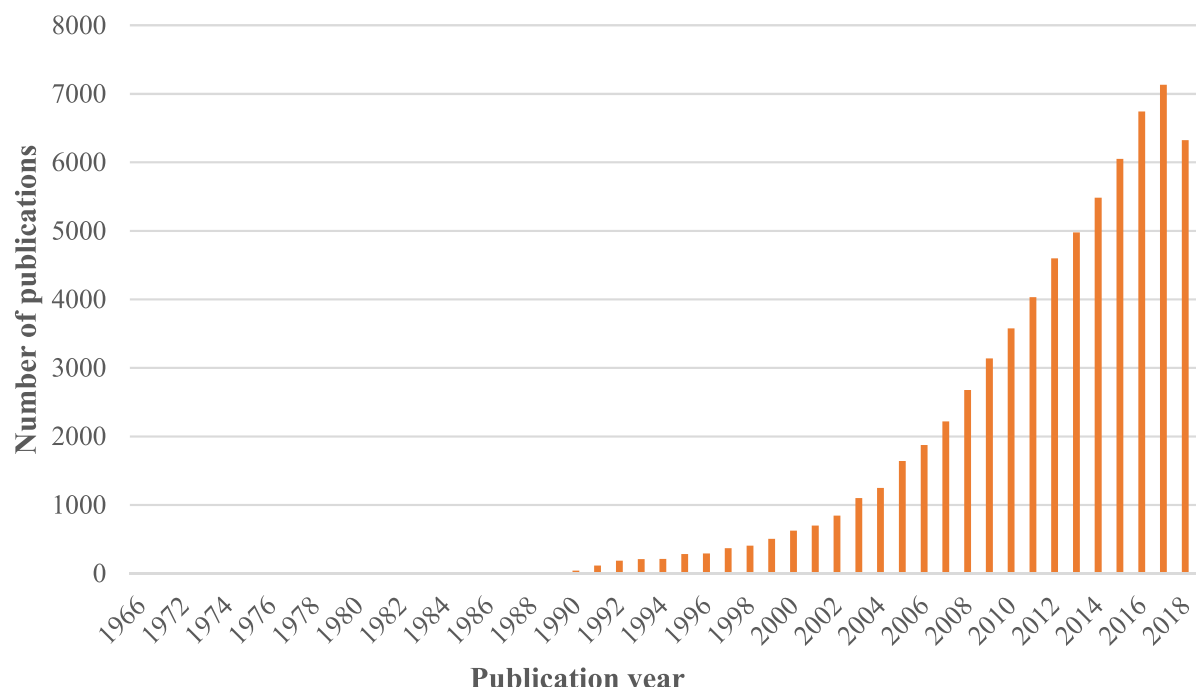

Fig. 1 Distribution of publications on health equity from 1966 to 2018

instead, references published in certain years are particularly frequently cited, which appear as distinct peaks in the frequency distribution curves over reference publication years (RPYs). This is usually caused by some important works in the development of the research.

We followed the two-step approach in RPYS $[19,20]$ using the programs rpys.exe and yearcr.exe developed by Marx et al. recently [22].

\section{Step one - identifying important RPYs}

The total number of cited references for each RPY and its deviation from the adjacent five-year (covering the two previous and two following years) median were calculated. The significant peaks across RPYs were identified through deviations of the number of cited references (DoNCR) from the adjacent five-year median using the following rules: (1) For the many small peaks prior to 1950, only those exceeding the upper limit of the 95\% confidence interval (CI) of DoNCR for the small peaks were considered significant. Two historical periods were identified, with an upper 95\% DoNCR CI limit of 12.18 for $1800-1899$ and 35.20 for 1900-1949; (2) All peaks appeared outstanding after 1950 and were identified as significant. This resulted in a total of 21 peaks.

\section{Step two - identifying important works within the peaks in RPYs}

The importance of a reference was measured by the number of citations it attracted and its percentage to the total citations of all references published in the same RPY as the assessed reference. Previous studies showed that citation patterns evolved over the years, changing from a concentration on some single publications in the 19th and early twentieth century to a focus on the most recent publications since late twentieth century $[19,20]$. We followed the same rule in identifying the seminal works: the most cited reference for each peak year prior to 1950 and references with a higher frequency of citation for the years after 1950 compared to those of the cited references published in the preceding and following two years (excluding the years with peaks). Since citations have become increasingly dispersed in recent years, the references with a citation exceeding the mean of the highest cited references published in the preceding and following two years (excluding the years with peaks) were retained for the RPYs since 1950. A total of 36 seminal works were identified.

The research team reviewed the identified seminal works. Those which provided non-specific methodological advice or with relatively low citations and weak relevance to health equity were further excluded. This resulted in a final list of 31 seminal works distributed in 17 peaks (four peaks without seminal works related to health equity) on health equity research. The influence of these seminal works was discussed under the context of the origin and development of health equity research categorized in line with the growth trend and disciplinary distributions of relevant publications.

The division of the development stages for a research area is generally based on the origin of terms and the growth in the speed of publications [27]. In this study, the period before the appearance of health equity terms was regarded as the origins stage. The stable growth of publications using health equity terms (including inequity, inequality and disparity) was labelled the formative stage. This was followed by a rapid development 
stage that featured exponential growth in the number of publications and an expansion stage that featured a plateau in the number of publications.

\section{Results}

Meltsner published the first article using the term "health and equality" in 1966. The growth of health equity studies was slow initially, with far less than 100 relevant publications each year. Since 1990, studies on health equity started to accelerate. The annual volume of publications on health equity eventually exceeded 1000 in 2003 and continued to grow until reaching the current level of 7132 in 2017 (Fig. 1). From 1900 to 2018, the majority were published in public health (e.g. $38.56 \%$ on public environmental occupational health) and health services (e.g. $13.56 \%$ on health care services and $8.73 \%$ on general internal medicine) journals, followed by social science journals (e.g. $6.06 \%$ in biomedical social sciences and $2.99 \%$ on social sciences other topics).

The cited references of health equity studies can be traced back to 1801 . The distribution of cited references by RPYs indicated a three-stage development in health equity studies (Fig. 2): origins (pre-1965), formative (1966-1990), and development and expansion (19912018). There were many small peaks in DoNCR in the origins stage, compared with a few major peaks occurring in the formative and development and expansion stages. In total, we identified 17 significant peaks with seminal works: 12 in the origins stage (Fig. 3), 2 in the formative stage (Fig. 4), and 3 in the development and expansion stage (Fig. 5).
Approximately 31 seminal works contributed to the 17 peaks (Table 1). Most of the seminal works were conducted by researchers in the US $(19,61.3 \%)$, the UK (7, 22.6\%) and the Netherlands (3, 9.7\%). The first seminal work conducted by Chadwick from Great Britain appeared in 1942, which revealed variations in life expectancy associated with social class. It signals the emergence of health equity studies. The ideology of health equity was eventually endorsed by the international society through the World Health Organization (WHO, 1946) declaration based on the foundational works of Chadwick (1842), Engels (1945), Durkheim (1897) and Du Bois (1899). Since then, the scope of health equity studies has been extended from a focus on mortality and morbidity to a view on health and wellbeing, from a wealth-related perspective to perspectives of a variety of social classifications (e.g. social stigma and discriminations), from quantitative descriptions to qualitative understanding of root causes, and from a national approach to an international approach. The WHO Commission on Social Determinants of Health (2005) provided a systematic framework for health equity studies.

\section{Origins stage (pre-1965)}

In a span of over one and a half centuries (1801-1965), 16 small peaks appeared (in 1842, 1845, 1848, 1855, 1859, 1897, 1899, 1939, 1942, 1946, 1948, 1950, 1951, 1954, 1958 and 1963), exceeding the upper limit of the 95\% CI of DoNCR (Fig. 3). But no seminal works were identified for the small peaks in 1848, 1855, 1859, and 1942.

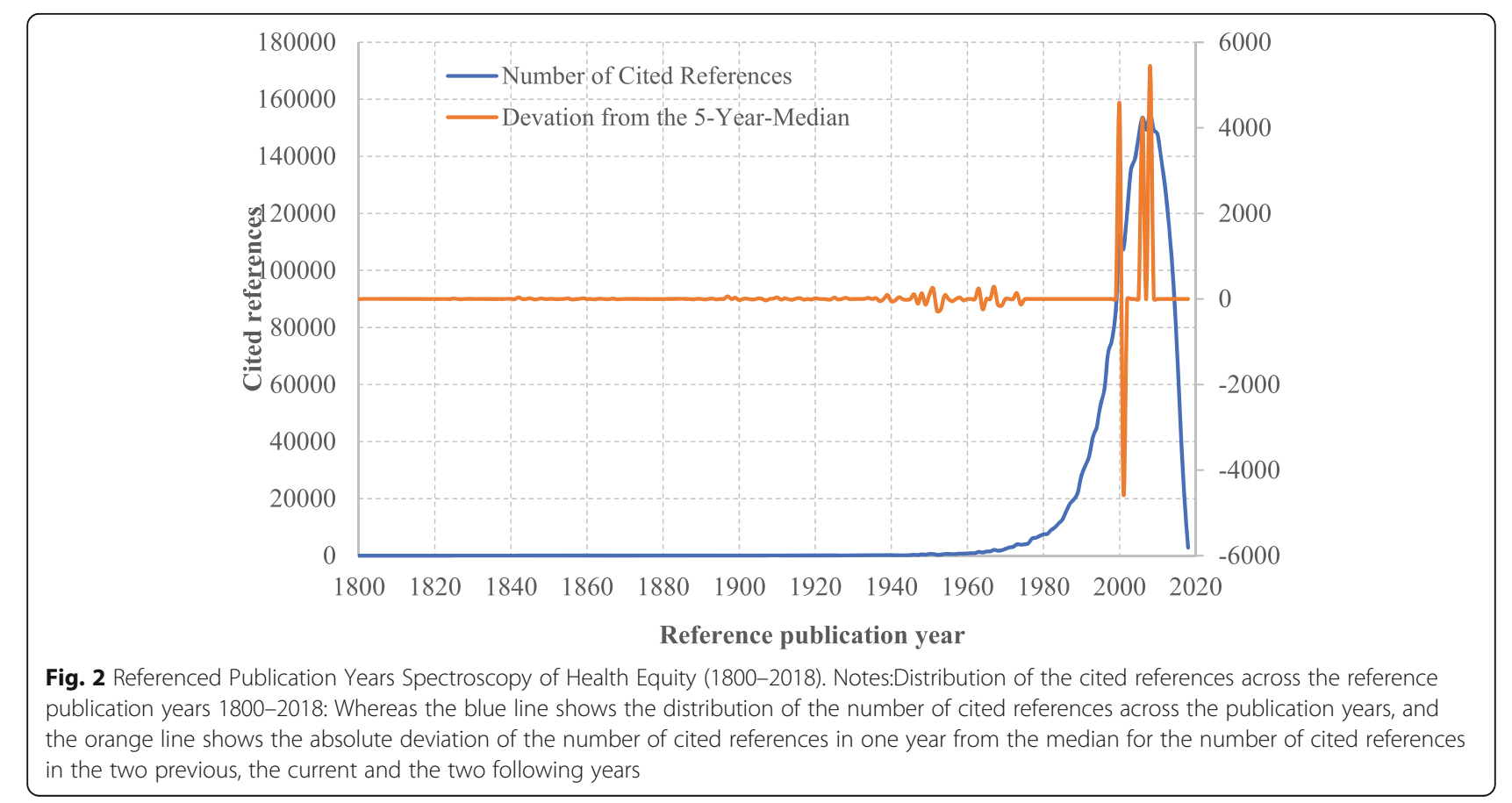




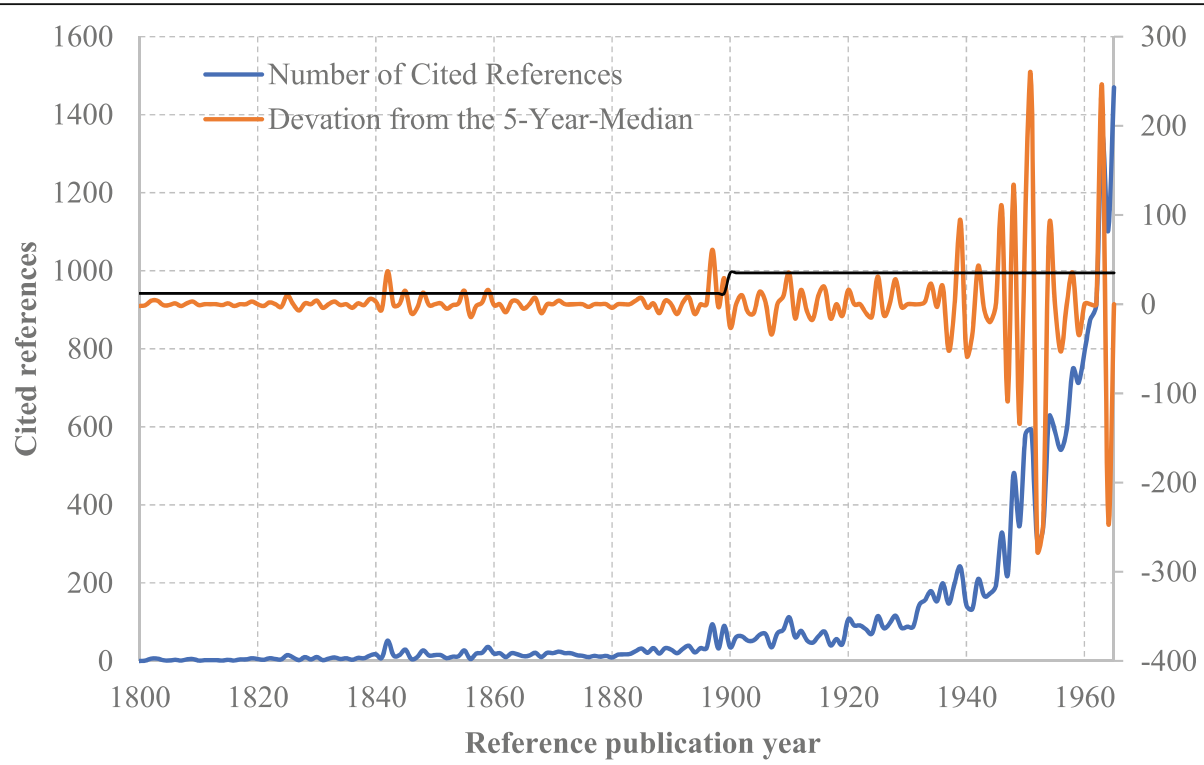

Fig. 3 Referenced Publication Years Spectroscopy of Health Equity (1800-1965). Notes:The peaks with seminal works appeared in 1842, 1845, 1897, 1899, 1939, 1946, 1948, 1950, 1951, 1954, 1958 and 1963. The peaks of 1848, 1855, 1859, and 1942 were without seminal works related to health equity

\section{Origins (1800-1899)}

Four significant peak RPYs were identified over the period from 1800 to 1899 , each featuring one publication. The four publications were all presented as books/reports, attempting to stratify health conditions according to social classes and groups. Chadwick (1842) from Great Britain [33] used evidence of variations in life expectancy to argue the importance of sanitary conditions and eventually contributed to the passing of the Public Health Act. Engels (1845), also from Great Britain [34], reported the shortage of the benefits of industrialization to the working class and their worse than pre-industrial living conditions. Durkheim (1897) from France [35] discussed suicide associated with residence and other sociodemographic factors. Du Bois \& Eaton (1899) from the US [36] were the first to study social and health problems in the black community in the context of racial segregation (details in Table 1). These works examined population health, in particular, environmental and occupational health issues, but did not focus much on healthcare systems, a major concern of

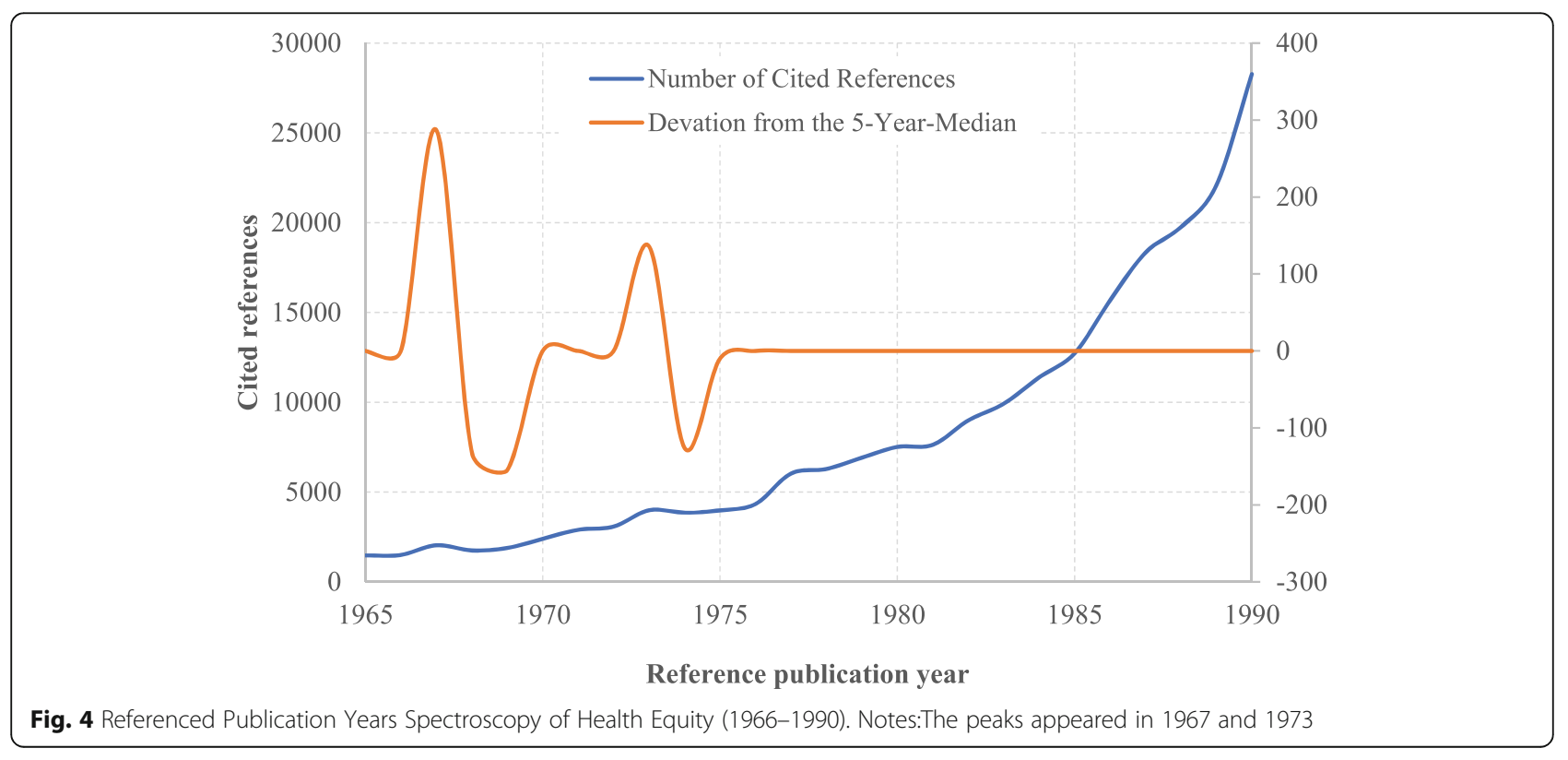




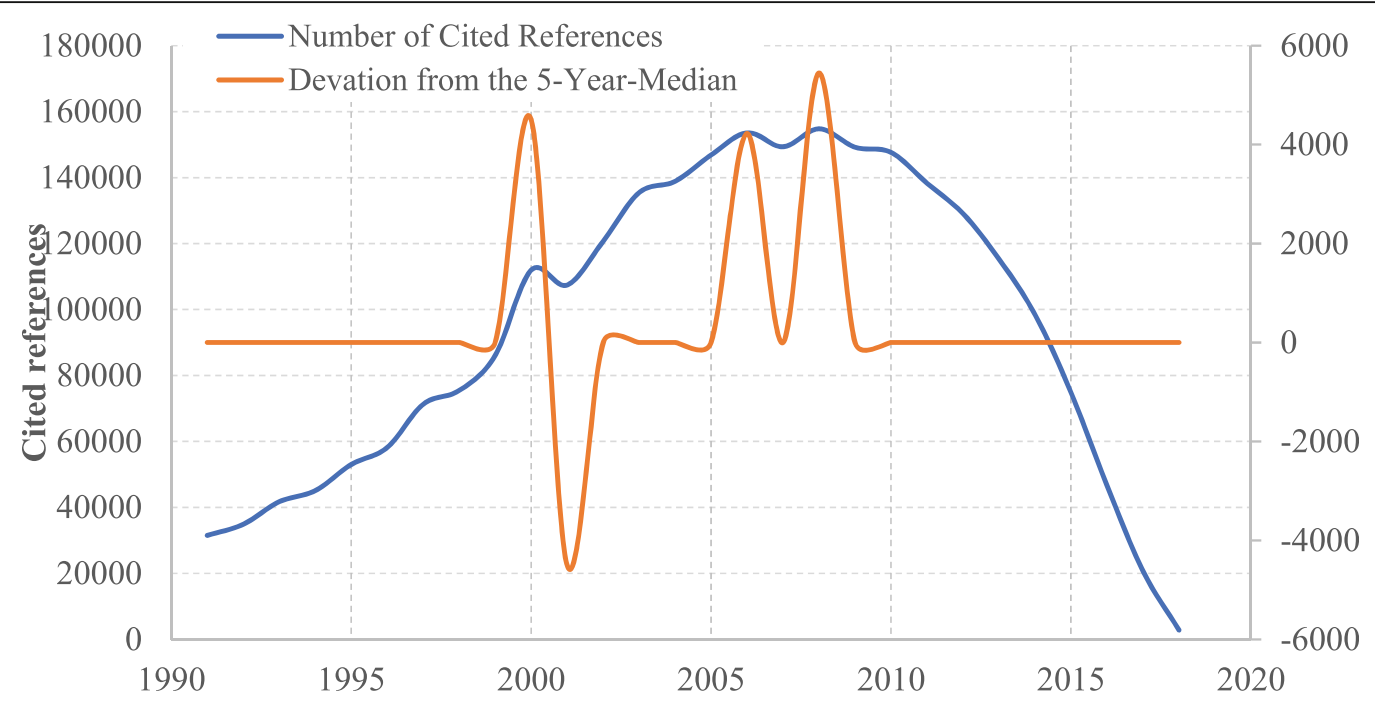

Reference publication year

Fig. 5 Referenced Publication Years Spectroscopy of Health Equity (1991-2018). Notes:The peaks appeared in 2000, 2006 and 2008

today's health equity studies. However, they unveiled the fact that there was a disproportional distribution of public health problems during the process of social and technological advancement.

\section{Early theoretical development (1900-1965)}

The period of 1900-1965 laid a critical theoretical and methodological foundation for the latter development of health equity studies. A total of 8 significant peak RPYs were identified for this period, involving 13 seminal works. These works contributed to the development of the "health as a human right" framework, social class theories, methodological approaches to statistical analyses on spatial distribution and social distribution of health, and measurements of health (No.5 to No.17 in Table 1).

The WHO (1946) [37] and the United Nations General Assembly (1948) [38] proposed that, as a fundamental human right, every human being is entitled to the highest attainable standard of health without the distinction of race, religion, political belief, economic or social condition. These works set up the basic tone and essential principles for health equity.

A series of studies conducted by sociologists in the US proposed social class theories, offering insights into how a social system can be described in terms of interactions between actors (Talcott, 1951) [39], how individuals compare with others and attach themselves to a social group (Festinger, 1954), how social groups contact and form prejudice against others (Allport et al., 1954) [40], and how social stigma which denies full social acceptance of some groups and individuals develops (Goffman,
1963) [41]. These theories were widely used in classifying social groups and help explain the underlying reasons for health inequity between socially advantaged and disadvantaged groups.

The unequal distribution of health was studied using a range of approaches. The seminal works included the ecological mapping of schizophrenia (Faris \& Dunham, 1939) [42] and exploration of social class differences in the treatment of mental illness (Hollingshead et al., 1958) [6]. Robinson (1950) [43] highlighted the importance of research into the correlations between mean outcomes and mean characteristics of social groups: correlations at the group level were much higher than those at the individual level.

The measurement of health was enhanced by incorporating the perspective of consumers. Cronbach's alpha (1951) was proposed for testing the reliability (or internal consistency) of instruments measuring patient-reported health outcomes [44]. The Kaplan-Meier estimator (1958) [45] was proposed as a nonparametric estimation method, solving the problem of the statistical testing of data that have a ranking but no clear numerical interpretation. The advancement of statistical methods and psychometric tests boosted the confidence of researchers in using subjective (patient-reported) health indicators. The Katz (1963) instrument measuring independence in activities of daily living (ADL) [46] gained wide acceptance. In addition, people's understanding about the function of health care systems, in particular in relation to health equity, was significantly improved by the work done by Nobel laureate, Kenneth Arrow, which summarized the special characteristics of the health care 
Table 1 Summary of the most frequently cited references (1800-2018) in health equity studies

\begin{tabular}{|c|c|c|c|c|c|c|}
\hline \multirow[t]{2}{*}{ No } & \multirow{2}{*}{$\begin{array}{l}\text { Reference } \\
\text { Publication } \\
\text { Year }\end{array}$} & \multirow[t]{2}{*}{ Authors, Title and Source } & \multirow[t]{2}{*}{ Country } & \multicolumn{2}{|c|}{ Citation of References } & \multirow[t]{2}{*}{ Brief summary } \\
\hline & & & & $\begin{array}{l}\text { Number (\%) } \\
\text { in the Peak } \\
\text { Year }\end{array}$ & $\begin{array}{l}\text { Total in } \\
\text { Google } \\
\text { Scholar }\end{array}$ & \\
\hline
\end{tabular}

\begin{tabular}{ll}
\hline $11842 \quad$ Chadwick E. Report on the Sanitary \\
& Condition of the Labouring Population of \\
& Great Britain: supplementary report on the \\
& results of special inquiry into the practice \\
& of interment in towns (Vol. 1). HM \\
& Stationery Office.
\end{tabular}

\author{
Great Britain
}

(76.92) 885

Engels $F$. The condition of the working class in England. Leipzig: Otto Wigand.

Great Britain

16

(55.18) 4560

31897

Durkheim, É. (1897). Le suicide.

France

58

(61.69) 1724
4 Du Bois WEB \& Eaton I. The Philadelphia Negro: a social study (No. 14). Published for the University.

51939 Faris REL \& Dunham HW. Mental disorders in urban areas: an ecological study of schizophrenia and other psychoses. Oxford, England: Univ. Chicago Press

World Health Organization (WHO). Constitution of the World Health Organization.
World Health Organization

56

(16.99) 2151 $\begin{array}{ll}71948 & \text { United Nations (UN) General Assembly. } \\ & \text { Universal declaration of human rights. UN } \\ & \text { General Assembly. }\end{array}$

81950
Robinson WS. Ecological correlations and the behavior of individuals. American Sociological Review, 15.
United Nations $83 \quad$ (17.34) 1078

USA

70

(12.05) 5720
The report highlighted variations in life expectancy associated with class or residency in statistics: middle-class people lived longer and healthier because they could afford to pay for sewage removal and fresh water connection to homes. The argument about the importance of sanitary conditions contributed to the passing of the Public Health Act and the Public Health Bill.

This book proposed that the industrial revolution made workers worse off: industrial workers had lower income, worse living environments and poorer health than their pre-industrial peers.

This book studied suicide and its social causes: suicide was found to be associated with nationality, religion, age, sex, race, marital status, economic status, educational level, family size, place of residence, and exposure to war conflicts.

This book presented the first statistical social study on a black community in the US: "Negro problem" was ostensibly "not one problem, but rather a plexus of social problems" caused by whites' enforcement of racial discrimination and a provision of unequal opportunity.

This book revealed a close relationship between mental disorders and the ecological structure of a city using ecological mapping: the distribution of schizophrenia was associated with sex, race, income, social relationship and home location.

The preamble of the $\mathrm{WHO}$ constitution defines health as "a state of complete physical, mental and social well-being and not merely the absence of disease or infirmity" and proposes that "the enjoyment of the highest attainable standard of health is one of the fundamental rights of every human being without distinction of race, religion, political belief, economic or social condition".

The declaration sets health as a fundamental human right and proposes that "everyone has the right to a standard of living adequate for the health and wellbeing of himself and of his family", and "motherhood and childhood are entitled to special care and assistance".

This study established ecological correlations (also spatial correlations) of behaviors of individuals: ecological correlations can measure the strength of a relationship and correlations at the group level can be much higher than those at the individual level.
77 
Table 1 Summary of the most frequently cited references (1800-2018) in health equity studies (Continued)

\begin{tabular}{|c|c|c|c|c|c|c|}
\hline \multirow[t]{2}{*}{ No } & \multirow{2}{*}{$\begin{array}{l}\text { Reference } \\
\text { Publication } \\
\text { Year }\end{array}$} & \multirow[t]{2}{*}{ Authors, Title and Source } & \multirow[t]{2}{*}{ Country } & \multicolumn{2}{|c|}{ Citation of References } & \multirow[t]{2}{*}{ Brief summary } \\
\hline & & & & $\begin{array}{l}\text { Number (\%) } \\
\text { in the Peak }\end{array}$ & $\begin{array}{l}\text { Total in } \\
\text { Google }\end{array}$ & \\
\hline
\end{tabular}

internal structure of tests. Psychometrika, 16(3), 297-334. processes. Human relations, 7(2), 117-140. estimation from incomplete observations. Journal of the American statistical association, 53(282), 457-481. and mental illness: Community study. Management of Spoiled Identity. New York: Simon and Shuster. index of ADL: a standardized measure of biologic and psychologic function. JAMA, 185, 94-99.

Cronbach's alpha (or coefficient alpha) for measuring reliability (internal consistency) of psychometric instruments/scales, which has since been widely adopted in studies in psychology, social sciences, business, nursing, and other disciplines.

This book presents a classic study on socia systems and the "Theory of Action", which laid a robust foundation for social systems theories and provided a theoretical framework for studies in a variety of areas, including medical practice, kinships and role-socialization, psychological relationships, and religious organization.

USA

$71 \quad(11.36) \quad 19,949$

This book extends the previous proposed theory of social comparison to studies appraising and evaluating abilities and opinions: how individuals evaluate their own opinions and abilities by comparing themselves to others in order to reduce uncertainty and learn how to define self.

This book redefines intergroup relationships and prejudice: the Allport's Scale was developed to measure prejudice ranging from ant locution to genocidal extermination.

USA

This study developed the Kaplan-Meier estimator, a nonparametric estimation method, for analyzing the survival function using incomplete lifetime data. It has fewer assumptions and is simpler compared with the parametric methods, which is particularly useful for data with a ranking but no clear numerical interpretations.

USA

This research monograph found a true link between social class and the distribution of mental illness being treated and the place of patients being treated in populations.

This book discusses how social stigma (e.g. social deviation, physical or mental defects) is developed and denies full social acceptance of some groups and individuals.

This study developed the ADL index measuring primary biological and psychosocial functions, and proposed the use of the ADL index as a tool for assessing the outcomes of clinical interventions which can guide clinical practices and help improve our understanding about aging.

This paper summarized the special characteristics of the medical care market: differences between the medical care market and a typical competitive market. It highlighted the uncertainty and welfare economics of medical care. This book describes the grounded theory,
a new interpretive approach (compared 
Table 1 Summary of the most frequently cited references (1800-2018) in health equity studies (Continued)

\begin{tabular}{|c|c|c|c|c|c|c|}
\hline \multirow[t]{2}{*}{ No } & \multirow{2}{*}{$\begin{array}{l}\text { Reference } \\
\text { Publication } \\
\text { Year }\end{array}$} & \multirow[t]{2}{*}{ Authors, Title and Source } & \multirow[t]{2}{*}{ Country } & \multicolumn{2}{|c|}{ Citation of References } & \multirow[t]{2}{*}{ Brief summary } \\
\hline & & & & $\begin{array}{l}\text { Number (\%) } \\
\text { in the Peak }\end{array}$ & $\begin{array}{l}\text { Total in } \\
\text { Google }\end{array}$ & \\
\hline
\end{tabular}

for qualitative research. Nursing research,

17(4), 364

191967

Antonovsky A. Social class, life expectancy Israel and overall mortality. The Milbank

Memorial Fund Quarterly, 45(2), 31-73.

201973

Kitagawa EM \& Hauser PM. Differential mortality in the United States: A study in socioeconomic epidemiology.

USA
264

(6.62) 2095

$21 \quad 1973$

$22 \quad 2000$

Berkman LF \& Kawachi I. Social Epidemiology.
232000

Office of Disease Prevention and Health Promotion, US Department of Health and Human Services: Healthy People 2010. http://www.health/gov/healthypeople/. Unequal treatment: Confronting racial and ethnic disparities in health care.

USA

$1303 \quad(1.16) \quad 1728$

USA

$2289 \quad(1.69) \quad 7003$

$25 \quad 2005$

Marmot M. Social determinants of health inequalities. The lancet, 365(9464), 1099 1104.

$\begin{array}{lll}\text { UKWHO } & 582 & (0.40) \quad 8790\end{array}$

Galobardes B, Shaw M, Lawlor DA, Lynch JW \& Smith GD. Indicators of socioeconomic position (part 1). Journal of Epidemiology \& Community Health, 60(1), 7-12.

with the positivism approach) to

qualitative studies on emerging social and cultural issues. According to the grounded theory, new theories arise from qualitative data. This approach has since been widely endorsed by the international research community.

$115 \quad(5.64) \quad 1019$

This study revealed class influences on one's chance of alive: the largest class difference existed in the middle years of life.

This book presents findings of a study that revealed differential mortality across a broad spectrum of social and economic factors (including age, sex, education, income, occupation, race, marital status, parity, nativity, and geographic classifications): lower socioeconomic status is associated with higher risks of dying and lower life expectancy.

This study provided a widely-accepted framework for operationalizing assessment of "equitable distribution of health services": health care utilization is determined by both need factors and enabling factors at the individual, household and societal levels.

This is the first book of social epidemiology, describing a new subdiscipline in the field of epidemiology that focuses particularly on the effects of social class on health.

This US governmental document depicts two overarching goals: to enhance life expectancy and the quality of life and to eliminate health disparities between different segments of the population. It contributed to the development of various models measuring disparities.

This Institute of Medicine report warned that racial and ethnic minorities received lower quality healthcare than whites, and the bias, prejudice and stereotyping of healthcare providers might have contributed to the unequal treatment. A comprehensive multi-level strategy was proposed to eliminate these disparities.

This paper describes the tasks of the WHO Commission on Social Determinants of Health, addressing social factors leading to ill health and health inequity. It not only reviewed the existing body of knowledge but also raised societal debates on health inequalities within and between countries.

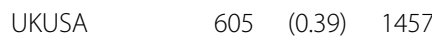

This study presents a comprehensive list of indicators measuring socioeconomic position (SEP) that were commonly used in health research (education, income, housing characteristics, occupation, occupational based measures, proxy 
Table 1 Summary of the most frequently cited references (1800-2018) in health equity studies (Continued)

\begin{tabular}{|c|c|c|c|c|c|c|}
\hline \multirow[t]{2}{*}{ No } & \multirow{2}{*}{$\begin{array}{l}\text { Reference } \\
\text { Publication } \\
\text { Year }\end{array}$} & \multirow[t]{2}{*}{ Authors, Title and Source } & \multirow[t]{2}{*}{ Country } & \multicolumn{2}{|c|}{ Citation of References } & \multirow[t]{2}{*}{ Brief summary } \\
\hline & & & & $\begin{array}{l}\text { Number (\%) } \\
\text { in the Peak } \\
\text { Year }\end{array}$ & $\begin{array}{l}\text { Total in } \\
\text { Google } \\
\text { Scholar }\end{array}$ & \\
\hline
\end{tabular}

indicators, composite indicators, and area level measures): the theoretical basis, measurement, interpretation, strengths and

$27 \quad 2006$ Wilkinson RG \& Pickett KE. Income inequality and population health: a review and explanation of the evidence. Social science \& medicine, 62(7), 1768-1784.

$28 \quad 2006$

Van Doorslaer E, Masseria C, \& Koolman X. Inequalities in access to medical care by income in developed countries. Canadian medical association journal, 174(2), 177183.

Netherlands,UK, $341 \quad(0.22) \quad 825$ OECD countries $487 \quad(0.32) \quad 1536$ limitations of each indicator.

UK

(1)

This paper reviewed the relationship between income inequality and inequality in population health, and proposed that income distribution is a convenient and widely applicable measure for socioeconomic stratifications.

This study examined inequity in the use of physician services (in 2000) in the 21 OECD countries using data extracted from the national household surveys. The study found that primary care (general practice) was pro-poor or distributed fairly equally, while specialist care tended to be pro-rich.

292008 Marmot M, Friel S, Bell R, Houweling TA,
Taylor S \& Commission on Social
Determinants of Health. Closing the gap in
a generation: health equity through action
on the social determinants of health. The
Lancet, 372(9650), 1661-1669.

UK, WHO 1929 (1.25) 4063

This paper summarized findings of the WHO Commission on Social Determinants of Health, and called for all governments to lead actions addressing social determinants of health with an aim to achieve health equity. The paper also set key action areas associated with daily living conditions and their underlying structural drivers.

$30 \quad 2008$

Mackenbach JP, Stirbu I, Roskam AJR, Schaap MM, Menvielle G, Leinsalu M \& Kunst AE. Socioeconomic inequalities in health in 22 European countries. New England Journal of Medicine, 358(23), 2468-2481.

Netherlands, $\quad 903 \quad(0.58) \quad 2383$
Sweden,
Estonia,
European Union
countries

This study compared the magnitude of inequalities in mortality and self-assessed health among the 22 European countries using a regression-based inequality index: inequalities in health varied across the European countries, which were associated with the socioeconomic status of each country.

O'donnell O, Van Doorslaer E, Wagstaff W \& Lindelow M. Analyzing health equity

Netherlands, World Bank $531 \quad(0.34) \quad 1656$ using household survey data.
This book provides researchers with a stepby-step practical guide to the measurement of various aspects of health equity: in access to health services, in financial contributions to health systems, and in health outcomes. This led to a more comprehensive approach to monitoring of the trends in health equity, understanding of the causes of health inequities, extensive evaluation of the effects of development programs on health equity, and development of effective policies and programs to reduce inequities in the health sector. market in comparison with a typical competitive market [47].

\section{Formative stage (1966-1990)}

Between 1966 and 1990, two large peak RPYs were identified (Fig. 4). For the first time, the term "health and equality" was used in the literature [13].

Over this period of time, large epidemiological studies were conducted to quantify the health gaps in populations.
Two epidemiological studies on social class differences in mortality were identified as seminal works. Antonovsky (1967) [48] revealed that social class influenced one's chance of being alive and class difference was the largest in the middle years of life. Kitagawa \& Hauser (1973) [49], in their study labelled "socioeconomic epidemiology", confirmed that mortality differentials existed across a broad spectrum of social and economic factors (No.19 to No.20 in Table 1). 
Inequity in healthcare services started to attract attention. Both healthcare and other social service systems were examined for their roles in addressing disparities in accessing health care. The Andersen health utilization model published in 1973 [50] provided a widely-accepted framework for operationalizing the assessment of the "equitable distribution of health services". It proposed that health care utilization is determined by both need factors and enabling factors at the individual, household and societal levels (No.21 in Table 1).

Over this period of time, qualitative research methods also started to gain mainstream recognition in the research community, thanks to the groundbreaking "grounded theory" (Glaser et al., 1967) [51] which provided a systematic methodological approach for researchers to study emerging social and cultural phenomena, including health inequity issues and develop new theories arising from qualitative data (No.18 in Table 1).

\section{Development and expansion stage (1991-2018)}

Three large peaks in RPYs appeared over the years between 1991 and 2018 (Fig. 5). The peak RPYs occurred only when several seminal works made significant cocontributions. A total of 10 seminal works over this period were identified, including two published in the non-peak RPYs (2003 and 2005). Seminal works in this stage featured the formulation of the new discipline "social epidemiology" and system perspectives on healthcare and health equity at national and international levels. Researchers from the UK played a leading role in the seminal works: $50.0 \%$ from the UK (5), followed by $40.0 \%$ from the US (4) and $30.0 \%$ from the Netherlands (3).

\section{Rapid development (1991-2005)}

Research on health equity entered a period of rapid development between 1991 and 2005. The peak RPY occurred in 2000 , accounting for $9.89 \%$ of all cited references $(1,132,343)$ published over this period. But not a single publication contributed over $1.33 \%$ of the citations, suggesting co-contributions of a number of seminal works. Four seminal works were identified for this period: two fell into the peak RPY (in 2000); the other two were published in 2003 and 2005, respectively (Table 1).

This period witnessed the official endorsement of the "concept and principles of equity in health" by the WHO in the early 1990s and the establishment of "social epidemiology" (Berkman and Kawachi, 2000) [52], a new sub-discipline of epidemiology focusing particularly on the effects of social class on health. The most influential works on health equity conducted at the national system level included "Healthy People 2010" promulgated by the US Department of Health and Human Services (in 2000) [3], and the Institute of Medicine (2003) report [53] on income and race-related disparities in health and healthcare. The US led in the development of national strategies for improving and monitoring the progress of health equity. At the global system level, Marmot's article "Social Determinants of Health Inequalities" (2005) on behalf of the WHO Commission on Social Determinants of Health [54] emphasized the importance of looking at the problem of health inequity beyond the traditional scope of health care services (No.22 to No.25 in Table 1).

\section{Plateaued expansion (2006-2018)}

Publications on health equity continued to grow from 2006. But citations of these publications appeared to experience a plateau (the decline of citations since the RPY of 2010 may possibly be offset by citations in future publications). Two peak RPYs were identified. The first peak occurred in 2006, contributing to $12.9 \%$ of the citations over this period, compared with $13.0 \%$ contributed by the second peak in 2008. Not a single publication contributed over $0.39 \%$ of the citations in the first peak RPY and $1.25 \%$ in the second peak RPY, respectively. Therefore, several papers in each peak RPY were identified as seminal works (Table 1).

Methods for health equity studies were further refined. Galobardes et al. (2006) $[55,56]$ presented a comprehensive list of indicators measuring the socioeconomic status of people, including the theoretical basis, measurements, interpretation, strengths and limitations of each indicator. O'Donnell, Van Doorslaer, Wagstaff \& Lindelow (2008) [57] developed a technical guideline entitled "Analyzing health equity using household survey data" on behalf of the World Bank, which covers the equity of health systems in structure (e.g. financial contributions), process (e.g. accessibility), and outcomes (income-related health outcomes).

Over this period, two seminal works compared health equity across countries: one among the Organization for Economic Co-operation and Development (OECD) countries (Van Doorslaer et al., 2006) [58]; and the other among the European Union countries (Mackenbach et al., 2008) [59].

This period also featured calls for action on the social determinants of health. Wilkinson and Pickett (2006) [60] proved that greater income inequalities are associated with poorer overall population health. The WHO Commission on Social Determinants of Health report "Closing the gap in a generation: health equity through action on the social determinants of health" (Marmot, 2008) [2] attracted the highest citation rate (1929, $1.25 \%$ ) over this period (No.26 to No.31 in Table 1).

\section{Discussions}

This study detected the historical roots and seminal works of health equity using RPYS. A total of 17 pronounced peaks in RPYs were identified over the years 
from 1800 to 2018. These citation peaks are indicative of milestone works in research on health equity: 31 seminal studies. The historical evolutionary path in health equity studies is characterized by three distinctive stages: origins (1800-1965), formative (1966-1991), development and expansion (1991-2018).

The origins stage (1800-1965) is in line with the development of modern public health. Poor sanitation and living conditions of the poor and working class were proved to be associated with high mortality and poor population health, triggering governmental interventions through public health acts. These populations were deemed highly susceptible to infectious diseases in epidemiology, and if not managed properly, could impose serious health risks to the entire society. At this stage, there was not much discussion about unequal access to health care services. Instead, environmental and occupational health and safety for the entire society was the major focus. However, the "Constitution of the World Health Organization" (1946) and the preamble to the United Nations "Universal Declaration of Human Rights" (1948) signals a development in conceptualizing health equity [18]. Since the 1950s, research instruments for studying health equity have been developed, providing theoretical and methodological foundations for research into health equity.

In the formative stage (1966-1990), the terms "health disparity", "health equality" and "health equity" were formally defined. Sociological studies made a significant contribution to the development of health equity research. This was driven, at least partly, by the grounded theory proposed by Glaser et al. (1967). This stage also features the wide acceptance of social class theories and their use in epidemiological studies. However, the lack of a specified sub-discipline and relevant research methods restricted the growth of health equity studies.

In the third stage (1991-2018), social epidemiology was established with a specific mission to study health equity issues. The concept of health equity was further clarified in the early 1990s $[15,16]$. Researchers started to examine health equity issues from national and international perspectives based on the theory of health systems. Driven by the WHO and the World Bank, a consensus on the measurements of the social determinants of health and the methods for decomposing the contributions of socioeconomic factors on health equity was reached. This contributed to a rapid growth in health equity studies. The WHO proposed a global goal for achieving health equity through universal health coverage.

Overall, health equity studies have made a significant contribution in driving the global agenda of "health for all and health in all" [61, 62]. A systems approach beyond the health sector is recognized as essential for achieving health equity [63]. Researchers from the UK, the US, and the Netherlands led the development and growth of research into health equity. This finding is consistent with previous studies [15, 64]. The WHO was the leading agency driving the agenda of health system development with a strong focus on health equity. The efforts of the WHO were supported by its member countries, the World Bank, regional organizations such as the OECD and the European Union, and many non-governmental organizations (NGOs). However, scant studies have been conducted from a political perspective [65, 66], although actions on the social determinants of health are often intensely political [67]. Some researchers have called for increasing attention on socio-political analyses of health equity studies, which will not only offer novel theoretical insights but also methodological innovations $[68,69]$.

Significant progress has been achieved in measuring health equity $[55,56,66,70-75]$ and decomposing contributions of various determinants of health inequity [76-82]. But there is a lack of understanding of the pathways and mechanisms of how the social determinants of health lead to health inequalities. The existing studies are criticized for a bias towards socioeconomic factors (e.g. income level, social class, educational achievement, and occupational status), midstream factors (e.g. biology, health-related behaviors, environment, and health benefits) and downstream factors (e.g. healthcare services access and use factors) [67]. This has limited the usefulness of health equity studies in political and policy decision making [83-85]. Recently, several theoretical frameworks have been proposed to facilitate research into the causal pathways between upstream social determinants of health (e.g. material, social, political, and cultural circumstances) and health inequity [86-88], such as social disadvantage and life course approaches [89, 90]. The focus of health equity studies has been extended to concerns of a much broader range of socioeconomic and upstream factors, such as poor health services and health outcomes experienced by the sexual minorities [91-93] and those with disabilities and mental health problems $[66,94]$ as a results of victimization and discrimination compounded by stigma $[95,96]$. However, there is a lack of understanding about how these factors interact with other socioeconomic factors [96]. Dover and Belon developed a framework integrating the existing social determinants of health framework and the health services utilization framework [97]. It is expected that more studies will emerge addressing health equity concerns from an economic perspective [98-100]. Despite the progress, health equity studies remain a challenge due to the long and complex causal pathways linking individual and social factors to health and our limited ability to study this topic using randomized control trials [89]. 


\section{Conclusions}

The historical origins of health equity research can be traced back to the early 1800 s and is embedded in the development of public health. It has become a major focus of the sub-discipline of social epidemiology, involving a set of measurements and methodological approaches. Sociological studies made a significant contribution to the development of social epidemiology. The concept and principles of heath equity have now been widely accepted in the international community thanks to the efforts of the WHO. Health equity studies are moving from evidence gathering to the identification of cost-effective policies and governmental interventions. This may lead to the emergence of another sub-discipline "Political Epidemiology" as suggested by Pega and Kawachi from Harvard University [101]. New frameworks and analytic approaches are needed to investigate the causal pathways between the social determinants of health and health inequalities [88, 97].

\section{Limitations}

There are several limitations in this study. Firstly, this RPYS study relied on the WoS collection, similar to previous RPYS studies. The WoS database covers high quality journals. But it is biased toward publications in the English language. However, the RPYS method has a focus on references, which expands the coverage of publications and may also reduce the language bias. Secondly, the RPYS does not analyze citation relationships and networks. Future studies should consider the use of co-citation analyses, bibliographic coupling, and direct citations in consideration of research fronts [102].

\section{Abbreviations \\ ADL: Activities of daily living; Cl: Confidence interval; DoNCR: Deviations of the number of cited references; MDGs: Millennium Development Goals; NGOs: Non-governmental organizations; OECD: Organization for Economic Co-operation and Development; RPY: Reference publication years; RPYS: Referenced publication year spectroscopy; SDGs: Sustainable Development Goals; WHO: World Health Organization; WoS: Web of Science}

\section{Acknowledgments}

The support provided by the China Scholarship Council (CSC) during a visit of Qiang Yao to La Trobe University is acknowledged (No. 201806275011).

\section{Authors' contributions}

Qiang Yao contributed to the study design, data analyses, data interpretation, and drafting of the manuscript. Xin Li, Fei Luo and Lianping Yang contributed to the data collection and analyses. Chaojie Liu contributed to the extraction of themes, interpretation of results and writing of the manuscript. Ju Sun contributed to the study design and data interpretation of the manuscript. All authors have read and approved the final version of the manuscript.

\section{Funding}

The study was funded by the National Natural Science Foundation of China (grant numbers 71603188 and 71603292), the Humanity and Social Science Youth Foundation from the Ministry of Education of China (grant numbers 16YJCZH137), the National Social Science Foundation of China (grant numbers 16GBL150).

\section{Availability of data and materials}

The datasets analyzed during the current study are available in the Web of Science Core Collection, [www.webofknowledge.com].

Ethics approval and consent to participate

Not applicable.

\section{Consent for publication}

Not applicable.

\section{Competing interests}

The authors declare that they have no conflict of interest.

\section{Author details}

${ }^{1}$ School of Political Science and Public Administration, Wuhan University, Wuhan 430072, Hubei, China. ${ }^{2}$ School of Psychology and Public Health, La Trobe University, Melbourne, VIC 3086, Australia. ${ }^{3}$ School of Information Management, Wuhan University, Wuhan 430072, Hubei, China. ${ }^{4}$ Union Hospital, Tongji Medical College, Huazhong University of Science and Technology, Wuhan 430022, Hubei, China. ${ }^{5}$ School of Public Heath, Sun Yat-sen University, Guangzhou 510275, Guangdong, China. ${ }^{6}$ Institute of Health, Wuhan University, Wuhan 430071, Hubei, China.

Received: 4 June 2019 Accepted: 23 September 2019

Published online: 15 October 2019

\section{References}

1. World Health Organization: Health in 2015: from MDGs, millennium development goals to SDGs, sustainable development goals. 2015.

2. Marmot M, Friel S, Bell R, Houweling TA, Taylor S. Commission on social determinants of health: closing the gap in a generation: health equity through action on the social determinants of health. Lancet. 2008;372: 1661-9.

3. Office of Disease Prevention and Health Promotion: US Department of Health and Human Services: Healthy People 2010. https://www.cdcgov/ nchs/healthy_people/hp2010htm 2000.

4. Goddard M, Smith P. Equity of access to health care services: theory and evidence from the UK. Soc Sci Med. 2001;53:1149-62.

5. Sen A. Why health equity? Health Econ. 2002;11:659-66.

6. Hollingshead AB, Redlich FC. Social class and mental illness: community study; 1958

7. Peter F. Health equity and social justice. J Appl Philos. 2001;18:159-70.

8. National Academies of Sciences Engineering Medicine: Communities in action: pathways to health equity. National Academies Press; 2017.

9. Culyer AJ, Wagstaff A. Equity and equality in health and health care. J Health Econ. 1993;12:431-57.

10. Chang $W$. The meaning and goals of equity in health. J Epidemiol Community Health. 2002;56:488-91.

11. Whitehead M. The concepts and principles of equity and health. Health Promot Int. 1991;6:217-28.

12. Braveman P. Health disparities and health equity: concepts and measurement. Annu Rev Public Health. 2006;27:167-94.

13. Meltsner M. Equality and health. Univ Pa Law Rev. 1966;115:22-38.

14. Almeida-Filho N, Kawachi I, Filho AP, Dachs JNW. Research on health inequalities in Latin America and the Caribbean: bibliometric analysis (19712000) and descriptive content analysis (1971-1995). Am J Public Health. 2003;93:2037-43.

15. Bouchard L, Albertini M, Batista R, De Montigny J. Research on health inequalities: a bibliometric analysis (1966-2014). Soc Sci Med. 2015;141: 100-8.

16. Cash-Gibson L, Rojas-Gualdrón DF, Pericàs JM, Benach J. Inequalities in global health inequalities research: A 50-year bibliometric analysis (19662015). PLoS One. 2018;(13):e0191901.

17. Gibbons MC. A historical overview of health disparities and the potential of eHealth solutions. J Med Internet Res. 2005;7:e50.

18. Elizabeth F, Gonzalez AR. The history of health equity: concept and vision. Diversity \& Equality in Health \& Care. 2017;14:148-52.

19. Marx W, Bornmann L. Tracing the origin of a scientific legend by reference publication year spectroscopy (RPYS): the legend of the Darwin finches. Scientometrics. 2013;99:839-44. 
20. Marx W, Bornmann L, Barth A, Leydesdorff L. Detecting the historical roots of research fields by reference publication year spectroscopy (RPYS). J Assoc Inf Sci Technol. 2014;65:751-64.

21. Elango B, Bornmann L, Kannan G. Detecting the historical roots of tribology research: a bibliometric analysis. Scientometrics. 2016;107:305-13.

22. Leydesdorff L, Bornmann L, Marx W, Milojevic S. Referenced publication years spectroscopy applied to iMetrics: Scientometrics, journal of Informetrics, and a relevant subset of JASIST. Journal of Informetrics. 2014;8: $162-74$.

23. Wray KB, Bornmann L. Philosophy of science viewed through the lense of "referenced publication years spectroscopy" (RPYS). Scientometrics. 2014 102:1987-96.

24. Comins JA, Hussey TW. Detecting seminal research contributions to the development and use of the global positioning system by reference publication year spectroscopy. Scientometrics. 2015;104:575-80.

25. Soheili F, Khasseh AA. Historical origins of information behavior research by reference publication year spectroscopy. Iranian journal of Information Processing \& Management. 2015;31:3-26.

26. Khasseh AA, Mokhtarpour R. Tracing the historical origins of knowledge management issues through referenced publication years spectroscopy (RPYS). J Knowl Manag. 2016;20:1393-404.

27. Hou J. Exploration into the evolution and historical roots of citation analysis by referenced publication year spectroscopy. Scientometrics. 2017;110:1437-52

28. Marx W, Haunschild R, Thor A, Bornmann L. Which early works are cited most frequently in climate change research literature? A bibliometric approach based on reference publication year spectroscopy. Scientometrics. 2017:110:335-53.

29. Rhaiem M, Bornmann L. Reference publication year spectroscopy (RPYS) with publications in the area of academic efficiency studies: what are the historical roots of this research topic? Appl Econ. 2017;50:1442-53.

30. Geraei E, Shakibaei F, Mazaheri E. Depression: detecting the historical roots of research on depression prevention with reference publication year spectroscopy. Int J Prev Med. 2018;9:53.

31. Yeung AWK, Wong NSM, Leung YY. Are coronectomy studies being cited? A bibliometric study. Journal of Investigative and Clinical Dentistry. 2018;10: e12366.

32. Bornmann L, Haunschild R, Leydesdorff L. Reference publication year spectroscopy (RPYS) of Eugene Garfield's publications. Scientometrics. 2018; 114:439-48.

33. Chadwick E: Report on the sanitary condition of the labouring population og great: Britain: supplementary report on the results of special inquiry into the practice of interment in towns. HM Stationery Office; 1842.

34. Engels F. The condition of the working class in England. Routledge: The Sociology and Politics of Health; 2005. p. 22-7.

35. Durkheim E: Le suicide: étude de sociologie. Alcan; 1897.

36. Du Bois WEB, Eaton I. The Philadelphia negro: a social study: Published for the University; 1899

37. World Health Organization: Constitution of the world health organization. 1995.

38. Assembly UN General: universal declaration of human rights. UN General Assembly 1948.

39. Parsons T. The social system; 1951.

40. Allport GW, Clark K, Pettigrew T. The nature of prejudice; 1954.

41. Goffman E. Stigma: notes on the management of spoiled identity; 1963.

42. Faris REL, Dunham HW. Mental disorders in urban areas: an ecological study of schizophrenia and other psychoses; 1939.

43. Robinson WS. Ecological correlations and the behavior of individuals. Int J Epidemiol. 2009;38:337-41.

44. Cronbach $\amalg$. Coefficient alpha and the internal structure of tests. Psychometrika. 1951;16:297-334.

45. Kaplan EL, Meier P. Nonparametric estimation from incomplete observations. J Am Stat Assoc. 1958;53:457-81

46. Katz S. Studies of illness in the aged. The index of ADL: a standardized measure of biologic and psychologic function. JAMA. 1963;185:94-9.

47. Arrow KJ. Uncertainty and the welfare economics of medical care. Am Econ Rev. 1963;53:941-73.

48. Antonovsky A. Social class, life expectancy and overall mortality. The Milbank Memorial Fund Quarterly. 1967;45:31-73.

49. Kitagawa EM, Hauser PM. Differential mortality in the United States: a study in socioeconomic epidemiology; 1973.
50. Andersen R, Newman JF. Societal and individual determinants of medical care utilization in the United States. The Milbank Memorial Fund Quarterly Health and Society. 1973;51:95-124.

51. Glaser BG, Strauss AL, Strutzel E. The discovery of grounded theory; strategies for qualitative research. Nurs Res. 1968;17:364.

52. Berkman LF, Kawachi I. Social Epidemiology; 2000.

53. Smedley BD, Stith AY, Nelson AR. Unequal treatment: confronting racial and ethnic disparities in health care; 2003.

54. Marmot M. Social determinants of health inequalities. Lancet. 2005;365: 1099-104.

55. Galobardes B, Shaw M, Lawlor DA, Lynch JW, Smith GD. Indicators of socioeconomic position (part 1). J Epidemiol Community Health. 2006; 60:7-12.

56. Galobardes B, Shaw M, Lawlor DA, Lynch JW, Smith GD. Indicators of socioeconomic position (part 2). J Epidemiol Community Health. 2006;60: 95-101

57. O'Donnell O, Van Doorslaer E, Wagstaff A, Lindelow M: Analyzing health equity using household survey data: a guide to techniques and their implementation. The World Bank: 2007.

58. Van Doorslaer E, Masseria C, Koolman X. Inequalities in access to medical care by income in developed countries. Can Med Assoc J. 2006;174:177-83.

59. Mackenbach JP, Stirbu I, Roskam A-JR, Schaap MM, Menvielle G, Leinsalu M, Kunst AE. Socioeconomic inequalities in health in 22 European countries. N Engl J Med. 2008;358:2468-81.

60. Wilkinson RG, Pickett KE. Income inequality and population health: a review and explanation of the evidence. Soc Sci Med. 2006;62:1768-84.

61. Voorhoeve A, Ottersen T, Norheim OF. Making fair choices on the path to universal health coverage: a précis. Health Economics, Policy and Law. 2016; 11:71-7.

62. Donkin A, Goldblatt P, Allen J, Nathanson V, Marmot M. Global action on the social determinants of health. BMJ Glob Health. 2018;3:e000603.

63. Shankardass K, Renahy E, Muntaner C, O'Campo P. Strengthening the implementation of health in all policies: a methodology for realist explanatory case studies. Health Policy Plan. 2014;30:462-73.

64. Arul K, Mesfin A. The top 100 cited papers in health care disparities: a bibliometric analysis. J Racial Ethn Health Disparities. 2017:4:854-65.

65. Robbins JA. Health inequality is a political issue. BMJ. 2019;366:14694.

66. Dawes DE. The future of health equity in America: addressing the legal and political determinants of health. The Journal of Law, Medicine \& Ethics. 2018;46:838-40.

67. Marmot M, Allen JJ. Social determinants of health equity: American Public Health Association; 2014

68. Taylor S. Political epidemiology: strengthening socio-political analysis for mass immunisation-lessons from the smallpox and polio programmes. Global Public Health. 2009:4:546-60

69. Greenhalgh T. What have the social sciences ever done for equity in health policy and health systems? Int J Equity Health. 2018;17:124.

70. Harper S, Lynch J: Methods for measuring cancer disparities: using data relevant to Healthy People 2010 cancer-related objectives. National Cancer Institute Cancer Surveillance Monograph Series, No. 6. USA: 2005. NIH Publication; 2010

71. Breen N, Scott S, Percy-Laurry A, Lewis D, Glasgow R. Health disparities calculator: a methodologically rigorous tool for analyzing inequalities in population health. Am J Public Health. 2014;104:1589-91.

72. Asada Y. A framework for measuring health inequity. J Epidemiol Community Health. 2005;59:700-5.

73. Asada Y, Hurley J, Norheim OF, Johri M. A three-stage approach to measuring health inequalities and inequities. Int J Equity Health. 2014;13:98

74. Van Doorslaer E, Van Ourti T: Measuring inequality and inequity in health and health care. In The Oxford Handbook of Health Economics 2012.

75. Moonesinghe R, Beckles GL. Measuring health disparities: a comparison of absolute and relative disparities. PeerJ. 2015:3:e1438.

76. Wagstaff A, van Doorslaer E, Watanabe N. On decomposing the causes of health sector inequalities with an application to malnutrition inequalities in Vietnam. J Econ. 2003;1:207-23

77. Wagstaff A, Doorslaer VE, Watanabe N: On decomposing the causes of health sector inequalities with an application to malnutrition inequalities in Vietnam. The World Bank; 2001.

78. Kessels R, Erreygers G. Structural equation modeling for decomposing rankdependent indicators of socioeconomic inequality of health: an empirical study. Heal Econ Rev. 2016;6:56 
79. Heckley G, Gerdtham U-G, Kjellsson G. A general method for decomposing the causes of socioeconomic inequality in health. J Health Econ. 2016;48:89-106.

80. Erreygers G, Kessels R, Chen L, Clarke P. Subgroup decomposability of income-related inequality of health, with an application to Australia. Economic Record. 2018;94:39-50.

81. Erreygers G, Kessels R. Socioeconomic status and health: a new approach to the measurement of bivariate inequality. Int J Environ Res Public Health. 2017;14:673.

82. Kessels R, Erreygers $G$. A direct regression approach to decomposing socioeconomic inequality of health. Health Econ. 2019;28:884-905.

83. van Doorslaer EE, van Ourti $T$. Measuring inequality and inequity in health and health care; 2012.

84. Penman-Aguilar A, Talih M, Huang D, Moonesinghe R, Bouye K, Beckles G. Measurement of health disparities, health inequities, and social determinants of health to support the advancement of health equity. Journal of Public Health Management and Practice. 2016;22:S33.

85. Costa-Font J, Hernández-Quevedo C. Measuring inequalities in health: what do we know? What do we need to know? Health Policy. 2012;106:195-206.

86. Palmer RC, Ismond D, Rodriquez EJ, Kaufman JS. Social determinants of health: future directions for health disparities research: American Public Health Association; 2019

87. Duran DG, Pérez-Stable EJ. Novel approaches to advance minority health and health disparities research: American Public Health Association; 2019.

88. Adler NE, Cutler DM, Fielding JE, Glymour M, Koh HK. Addressing social determinants of health and health disparities. Published September. 2016;19.

89. Bharmal N, Derose KP. Felician M, Weden MM. Understanding the upstream social determinants of health. RAND: California; 2015.

90. Larson K, Russ SA, Kahn RS, Flores G, Goodman E, Cheng TL, Halfon N. Health disparities: A life course health development perspective and future research directions. In: In Handbook of life course health development. Springer, Cham; 2018. p. 499-520.

91. Booker CL, Rieger G, Unger JB. Sexual orientation health inequality: evidence from understanding society, the UK longitudinal household study. Prev Med. 2017;101:126-32.

92. Jennings L, Barcelos C, McWilliams C, Malecki K. Inequalities in lesbian, gay, bisexual, and transgender (LGBT) health and health care access and utilization in Wisconsin. Prev Med Rep. 2019:14:100864

93. Barnhill M, Lee J, Rafferty A. Health inequities among lesbian, gay, and bisexual adults in North Carolina, 2011-2014. Int J Environ Res Public Health 2017;14:835

94. Williams SL, Mann AK. Sexual and gender minority health disparities as a social issue: how stigma and intergroup relations can explain and reduce health disparities. J Soc Issues. 2017;73:450-61.

95. Nakkeeran N, Nakkeeran B. Disability, mental health, sexual orientation and gender identity: understanding health inequity through experience and difference. Health Research olicy and Systems. 2018;16:97.

96. Zeeman L, Sherriff N, Browne K, McGlynn N, Mirandola M, Gios L, Davis R, Sanchez-Lambert J, Aujean S, Pinto N. A review of lesbian, gay, bisexual, trans and intersex (LGBTI) health and healthcare inequalities. Eur J Pub Health. 2018.

97. Dover DC, Belon AP. The health equity measurement framework: a comprehensive model to measure social inequities in health. Int J Equity Health. 2019;18:36

98. Cookson R, Mirelman AJ, Griffin S, Asaria M, Dawkins B, Norheim OF, Verguet S, Culyer AJ. Using cost-effectiveness analysis to address health equity concerns. Value Health. 2017;20:206-12.

99. Lal A, Moodie M, Peeters A, Carter R. Inclusion of equity in economic analyses of public health policies: systematic review and future directions. Aust N Z J Public Health. 2018;42:207-13.

100. Kumanyika $S$. Health disparities research in global perspective: new insights and new directions. Annu Rev Public Health. 2012:33:1-5.

101. Pega F, Kawachi I, Rasanathan K, Lundberg O. Politics, policies and population health: a commentary on Mackenbach, Hu and Looman (2013). Soc Sci Med. 2013;93:176-9.

102. Boyack KW, Klavans R. Co-citation analysis, bibliographic coupling, and direct citation: which citation approach represents the research front most accurately? J Am Soc Inf Sci Technol. 2010;61:2389-404.

\section{Publisher's Note}

Springer Nature remains neutral with regard to jurisdictional claims in published maps and institutional affiliations.

\section{Ready to submit your research? Choose BMC and benefit from:}

- fast, convenient online submission

- thorough peer review by experienced researchers in your field

- rapid publication on acceptance

- support for research data, including large and complex data types

- gold Open Access which fosters wider collaboration and increased citations

- maximum visibility for your research: over $100 \mathrm{M}$ website views per year

At $\mathrm{BMC}$, research is always in progress.

Learn more biomedcentral.com/submissions 